\section{LIFE BETWEEN THE TIDES}

Biology of Intertidal Animals

By $R$. C. Newell. Pp. viii +555. (Logos in association with Elek Books: London, 1970.) 1608.

THIs is a very welcome book on the biology of intertidal animals and will undoubtedly prove most useful to students of zoology and marine biology. Obviously designed for this purpose, it is regrettable that the publishers have produced it at a price which fow students can afford. A paperback edition for $£ 3$ or less would surely have been possible, and it is hoped that the publishers will think again.

This "Biology of Intertidal Animals" is an individual account with special emphasis on aspects which clearly interest the author most: in this it is stimulating, but it is perhaps not as comprehensive as its title, bulk and price might suggest. After an introduction on the physical, chemical and biological features of the intertidal zone, there follows a chapter on the faunas of special habitats - crevices, seaweeds and rockpools-which will be particularly useful to students on field courses. Chapter 3 , on the establishment of zonation patterns, is a useful summary of recent research on larval settlement, and the chapter which follows on the maintenance of these patterns of zonation presents an interesting summary of the behavioural aspects of such common animals as the species of Littorina, Lasaea, Talitrus and Hydrobia. Mechanisms of feeding, factors affecting feeding; respiratory mechanisms; factors affecting the rate of oxygen consumption; thermal stress and desiccation, form sub. jects of other chapters. Inevitably, one must compare this book with J. A. C. Nicols's earlier and successful Biology of Marine Animals now available as a paperback. Nicols's book is not restricted to intertidal animals and is therefore wider in one sense in dealing more with fishes and physiology, and on the other is more limited in the detail on intertidal forms. Newell's book is therefore welcome because its approach is very different, especially in descriptions of behaviour: Nicols's approach is essentially that of a comparative physiologist; Newell is evidently more interested in the animal in the field.

One of the chief difficulties facing an author of a book of this kind is how far to describe the basic information on which the real discussions are based and how much to assume what is known by the reader or is available to him elsewhere. It is a matter of opinion whether "the process of respiration" (pp. 267-283) or the account of the general properties of respiratory pigments (p. 302) are really necessary, or whether this information should more properly be sought in a textbook of physiology in order to follow the discussions on "oxygen stores" and "anaerobiosis". Similarly, the account of learning in nereids (p. 155) seems to me to be a digression in an otherwise valuable and coherent section. One might also ask if chapter $\mathbf{5}$ describing feeding mechanisms is really necessary in order to provide the background necessary to the chapter which follows on "Factors affecting Feeding".

To me the most interesting sections were those on maintenance of zonation patterns, thermal stress and desiccation, and the factors affecting feeding and respiration, and I would rather have seen the approach adopted in these chapters extended to some other topics which have been omitted or dealt with rather briefly than to have these other sections describing the basic facts. There is nothing on nitrogenous excretion and little on osmotic stress or the factors of importance in intertidal estuarine habitats. There is no mention of the uricotelic metabolism of Littorina neritoides, for example, nor is there any account of Trueman's work on burrowing in certain bivalves or in the lugworm, or of the microfauna, of population ecology or of the adaptation and control of the reproductive method. In spite of these omissions, as the author says in his own preface, this book is "an attempt to account for the distribution of intertidal animals in physiological terms" and it will undoubtedly find a place in all departments of zoology where animals are still studied. It is a well produced book with clear illustrations and tables placed appropriately in the text. This is a book to stimulate students to further study of the biology of intertidal animals and to enlarge the horizons. of those attending merine courses who may not have had the opportunity to keep abreast of the literature which the author so ably reviews in the light of his own work.

R. Phinlips Dales

\section{FISH PARASITOLOGY}

\section{Aspects of Fish Parasitology}

Edited by Angela E. R. Taylor and R. Muller. (Symposia of the British Society for Parasitology, Vol. 8.) Pp. vii + 167. (Blackwell (Scientific): Oxford and Edinburgh, 1970.) $60 s$.

THE parasitology of fishes as an area of research has been enjoying a rapid and very gratifying recent expansion. Some investigations have concentrated on commercial species and on parasites obviously harmful to the host. Others-particularly those concerned with helminths and copepods-have been taxonomically oriented, and often have ignored the fish host. Still other studies, notably those in the Soviet Union, have displayed strong ecological emphasis. Notwithstanding, major gaps remain in our knowledge of the parasites of fishes. In the marin $\theta$ environment particularly, many species are as yet undescribed, not to mention the many host species whose parasite fauna has not received even cursory attention. New impetus for studies of parasites and diseases has been generated because of the expansion of aquaculture of fishes, and the predictable concurrent expansion of parasite and disease problems in species under cultivation. Other research areas deserving of more attention include the life cycles and ecological relations of helminths, helminth physiology, and the impact of parasites on host mortality rates.

This volume is a valuable addition to the burgeoning literature in fish parasitology. It contains a collection of six thorough and lucid papers-helminthological in emphasis - on parasites of certain freshwater and marine fishes. Papers by K. MacKenzie and D. Gibson and by H. H. Williams et al. provide valuable insights about the relation of the morphology, physiology and chemistry of the host gut to the helminth fauns of microenvironments within that habitat. MacKenzie and Gibson have also summarized available information, including new experimental data, about the life histories of several common helminth parasites of plaice and flounders. The physiology of fish parasites, last summarized in 1961 by Markov, is reviewed succinctly by C. Arme and M. Walkey. Emphasis is placed on new information derived during the past decade from in vitro and transplantation studies. A few of the more interesting crustacean and molluscan parasites of freshwater fishes have been considered by G. Fryer as examples of how such organisms contribute to the solution of zoogeographical problems. J. C. Chubb has sketched broadly both the present status of knowledge and the need for additional information about the parasites of British freshwater fishes. $\mathrm{He}$ has examined available parasitological data from oligotrophic, mesotrophic, and eutrophic lakes, and from various zones of flowing waters, comparing the parasite faunas of salmonoid and cyprinid fishes. C. R. Kennedy has described a very interesting systems approach to the population biology of helminths in freshwater fishes which is illustrated by flow diagrams of representative host-parasite systems.

Although of primary interest to parasitologists and fishery biologists, the articles should also benefit specialists 